\title{
EXPERIMENTAL SUBSTANTIATION OF PARAMETERS OF ASPIRATION SEPARATOR OF SUNFLOWER SEEDS
}

\author{
Volodymyr Bulgakov ${ }^{1}$, Serhii Kiurchev ${ }^{2}$, Semjons Ivanovs ${ }^{3}$, Juri Olt ${ }^{4}$ \\ ${ }^{1}$ National University of Life and Environmental Sciences of Ukraine, Ukraine; \\ ${ }^{2}$ Tavria State Agrotechnological University, Ukraine; ${ }^{3}$ Latvia University of Life Sciences and \\ Technologies, Latvia; ${ }^{4}$ Estonian University of Life Sciences, Estonia \\ semjons@apollo.lv
}

\begin{abstract}
Sunflower is the most important oilseed in many countries. Separation of the sunflower grain mixture by the difference of the aerodynamic characteristics of its components showed that the most perspective for the improvement of the quality and intensification is the process of its separation in the aspiration separator. A new design of an improved seed aspiration separator has been developed that carries out the technological process of separating the sunflower seeds using vibration processes. So, in the seed separator, the air flow of constant force through the sail elements leads to the imposition of forced vibrations on the central tube of the distributor of the supplied seeds, which leads to the creation of centrifugal forces in the sunflower seed feeding system. As a result of experimental studies, it was established that the rational speed of the air flow should be in the range 4.5$5.5 \mathrm{~m} \cdot \mathrm{s}^{-1}$, the most rational length of the aspiration channel is $0.8 \mathrm{~m}$, the diameter of the aspiration channel should be equal to $200 \mathrm{~mm}$. The obtained results of the experimental research may be used for the development and designing of production prototypes of the aspiration separators of grain mixtures.
\end{abstract}

Keywords: sunflower seeds, separation, air flow, vibration.

\section{Introduction}

Sunflower is the most important oilseed in many countries. The oil content in sunflower seeds is 40-52 \%. In Ukraine its area is about $14.8 \mathrm{mln}$. ha and the yield reaches 4.6-5.0 $\mathrm{t} \cdot \mathrm{ha}^{-1}$ [1].

One of the important stages of preparation for processing and storage of food grain and seeds for sowing is their subsequent processing, in particular, separation from impurities and separation into fractions [2-5]. At the same time, the process of separation of the grain mixture using air flow has become widespread [6]. As a rule, in the existing grain and seed cleaning machines the process of separation of grain and seeds by the air flow is carried out in aspiration channels of various designs.

In addition, it should be noted that each of the existing designs of the suction channels has a number of significant drawbacks, the main of which are the difficulty of setting, the high energy consumption, the low quality of separation of seeds into fractions and the insufficient quality of work with seeds of various humidity $[7-8,17]$.

Based on the analysis of the research results of many scientists, it can be concluded that for the implementation of the separation process of grain and seeds by the air flow the most used are vertical aspiration channels with lower discharge.

In this case, with a sufficiently simple design of the separator mentioned there is implemented a possibility to process bulk materials and to reach high efficiency and quality of the seed separation into fractions. In order to increase the efficiency of separation of seeds into fractions, it is desirable to create in the system of aspiration separation of seeds a self-oscillating mode of movement located in the aspiration channel of the central tube. A lot of published works are devoted to scientific research of the process of separation of grain and various crops, among which [5-6] should be noted.

Moreover, it was shown in [9-11] that in the central part of the suction channel the air flow rate is maximum and decreases closer to the walls, which worsens the conditions for the process of separation of seeds. At the same time, the lower zone of the air flow is used inefficiently, although, taking into account the different speeds of seeds soaring in different fractions, in this part of the space of the suction channel, the effect of improving the quality of separation of seeds into fractions can be obtained. Our proposed new design of a vibroaspiration separator with lower discharge and the creation of a self-oscillating motion of the central pipe will eliminate the above disadvantages.

In [15] the efficiency of the aspiration chamber was proved when cleaning the grain from such a contaminant as insects and mites. Also, similar results were obtained under the conditions of separation of high-quality grain [16].

The purpose of the work is to substantiate rational parameters of the aspiration separator of seeds. 


\section{Materials and methods}

The structural diagram of the new vibratory aspiration separator of seeds is presented in Fig. 1. As evident from the presented structural diagram (Fig. 1), in the vertical aspiration channel of the grain separator there is a central pipe 2, which is connected by elastic elements 7 to the aspiration channel 1 , which is a stationary pipe of a larger diameter. Thus, the central pipe 2 is movable, and this mobility is determined by the elasticity of the elements 7 .

The central movable pipe 2 is equipped with sailing elements 6 , which, under the action of the suction air flow, cause the central pipe 2 to perform periodic circular oscillatory movements at the angle $\beta$. On top of the central pipe 2 there is installed a removable seed distributor 3 of a conical shape. Using the removable seed dispensers 3 having a different angle at the apex of the cone, a different rate of the seed descent $V_{o}$ into the space of the aspiration channel is achieved. As a result of circular self-oscillatory movements of the central pipe 2 (around its longitudinal axis), which are created by the sailing elements 6 and the suction air stream, the initial movement of the seeds is achieved, when the seed 3 immediately leaves the distributor 3 not vertically downward but at a certain angle $\alpha$.

Thus, the design of the new vibratory aspiration separator allows changing its design parameters that provide such parameters as: the initial speed $V_{o}$ (changing the taper of the seed distributor 3); the rotation angles $\beta$ of the central pipe 2 during its self-oscillating circular movements (changing the size and shape of the sailing elements 6 , the stiffness of the elastic elements 7, as well as the speed of the suction air flow); the angle $\alpha$ of descent of the seeds into the space of the aspiration channel 1 (determined by the amplitude of the self-oscillating process of the central pipe 2), which leads to the separation of the seed mixture into the necessary fractions. During the experimental studies, there were developed and manufactured the laboratory facilities and the instruments, necessary for recording the results. Also, a methodology for a multivariate experiment and modern methods of statistical processing of the results were used [12-14]. The statistical simulation was done according to the BoxBenkin method, the adequacy of the obtained regression models was checked by the Fisher test, the significance of the coefficients of the regression models was determined by the Student criterion, the optimal values of the structural and kinematic parameters of the aspiration separator were found using the classical optimisation methods.

In the experimental study of the fractionation process of a multifractional bulk grain mixture in the aspiration separator of the design developed by us, we studied the impact of the air flow velocity in the aspiration channel of the separator upon the separation of the seed mixture into the necessary fractions, determined the required length of the vertical aspiration channel and its diameter, determined the diameter of the nozzle for the seed to enter the suction channel, justified the design parameters of the sail elements that are mounted on the central separator tube. For this, we designed and manufactured an experimental setup, the scheme of which is shown in Fig. 2.

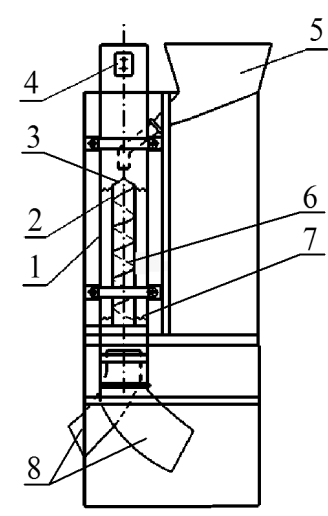

Fig. 1. Structural diagram of the new vibratory aspiration separator: 1 - suction channel; 2 - central pipe; 3 - seed distributor; 4 -fan; 5 - seed hopper; 6 - sail elements; 7 - elastic elements; 8 - seed distributor into fractions

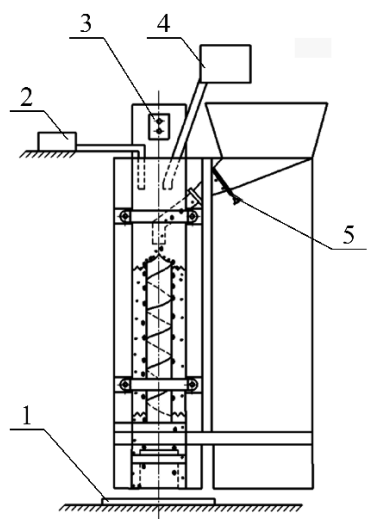

Fig. 2. Experimental setup for the research of the vibratory separator for sunflower seeds:

1 - capturing surface; 2 - Pitot-Prandtl tube; 3 - fan; 4 - anemometer; 5 - seed feed regulator 
It should be immediately noted that the right choice of the necessary air flow velocity in the aspiration channel, created by the fan, is an essential element in substantiating a justified design and kinematic parameters of the separator. When the air velocity is insufficient, the aerodynamic properties of the seeds do not lead to efficient splitting of the particle paths of individual fractions and at an excess velocity of the indicated flow, a significant part of the quality seeds will be carried up as the waste of light impurities. According to the developed methodology a fractional factorial experiment of the type $2^{4-1}$ was implemented. The repeatability of the measurement of the investigated parameters at each point was five. The following parameters were taken as the input parameters: the air velocity inside the aspiration channel; the rotation angle of the central pipe of the aspiration channel as a result of its self-oscillating movements; the rate of descent of the seeds from the distribution cone; the angle at which the seeds enter the space of the aspiration channel; the geometric dimensions of the cone element of the distributor. As the output parameters, the distribution of the seeds of the medium and heavy fractions is taken during their vibratory aspiration separation.

The air flow characteristics were studied using an experimental separator setup and laboratory measuring equipment, in particular, a Pitot-Prandtl tube, a liquid compensation micromanometer with a micrometer MKV-250 of a screw type, and an ARI-49 anemometer. As the working fluid denatured alcohol was used. The range of the measurements by the micromanometer was 0 to $250 \mathrm{~Pa}$, the permissible error was $0.02 \%$. The critical air flow rate was determined under the condition of extraction or hanging up inside the channel of the lightest from the separated seeds, using a specially developed methodology. Using as a criterion the maximum difference in the radii of seed dispersion between fractions, we obtained the value of the rational air velocity in the aspiration vertical channel of the separator, as well as the necessary energy consumption for the process under study. The conducted experimental investigations showed the results indicating that the sunflower seeds of the heavy fraction are stably concentrated around the base of the central tube of the vibratory aspiration channel and, by all means, will fall into the corresponding branch-off channel and the seed hopper of the heavy fraction. The seeds of the medium fraction fall down along their paths of the movement and are concentrated around the lower base of the central pipe already at a greater radius from its longitudinal axis and, accordingly, will, by all means, fall into their arcuate outlet channel and the hopper of the middle fraction. The light (defective) sunflower seeds, dust and other small particles are discharged outside the separator through its upper part.

In order to build a calibration curve, an ARI-49-type anemometer was used, which was installed at certain points of the vertical channel opposite the direction of the air flow. After that, at each of the same points, using the Pitot-Prantl tube, the readings of the MKV-250 micromanometer were recorded. The critical air flow rate was determined under the condition of exit or hanging-up inside the channel of the lightest of the separated seeds. Under the lower end of the aspiration channel, at the distance of placement of the hoppers-fraction separators $($ about $10 \mathrm{~cm}$ ) there was mounted a horizontal surface, which, by its dimensions, exceeded the diameter of the aspiration channel at least by $20 \%$. On the plate there were marked the centre of the aspiration channel and the radii from 10 to $300 \mathrm{~mm}$, with a step of $10 \mathrm{~mm}$. The surface of the plate was coated with a thin layer (0.5-1.0 mm) of Litol-24 grease. Next, 10 marked seeds of different densities were thrown exactly into the centre, and, by means of a calliper, the radii of the spread of the sunflower seeds were determined, calculating the average value and dispersion. A series of investigations was repeated, changing by means of a regulator the rate of the air flow from 0 to $150 \%$ of the critical speed in $10 \%$ increments, using the Pitot-Prandtl tube for the control. Applying the maximum difference in the radii of spacing between the fractions of the seeds as a criterion for evaluation, we obtained the value of the rational speed of the air flow in the vertical aspiration channel of the separator, as well as the necessary energy consumption for the separation process.

It was also found that at an insufficient length of the aspiration channel of the separator, the trajectories of the movement of the particles of the sunflower seeds will be too close to achieve clear separation of the fractions, but at a great length of the vertical channel excessive consumption of energy and increase in the height of the hopper installation are observed. In addition, a probability increases of repeated suspension of the rotating sunflower seeds, split in their way from the wall to the centre of the aspiration channel, which accordingly impairs the quality of the fractionation. Therefore, to determine the length of the aspiration channel according to the methodology of the previous 
experiment, the research was repeated, changing the height of the seed throwing in relation to the lower end of the vertical aspiration channel of the separator within the range from $0 \mathrm{~mm}(10 \mathrm{~cm}$ from the plane of the hoppers-separators), and to $1.0 \mathrm{~m}$ after every $10 \mathrm{~mm}$ to the maximum length of the vertical channel of the separator, i.e. to its upper part with the fan blades. The obtained results made it possible to draw a conclusion regarding the searched most rational length of the aspiration channel.

An excessive diameter of the aspiration channel leads to significant energy consumption, especially, when creating an air flow of high productivity. To study the impact of the diameter of the aspiration channel upon the performance of the separator, a device for fixing and feeding seeds was developed, which was produced on the basis of an electromagnetic relay of the RES-6 type, with a clamp for seeds. After the necessary repeatability throwing each of the 10 marked seeds according to the previous method was ensured, the smallest distance from the seed to the nearest wall of the vertical aspiration channel of the separator was measured, and its average value and dispersion were determined. As a result, the maximum seed feeding distance was obtained in the upper part of the vertical aspiration channel of the separator.

Besides, in order to produce an array of the data obtained as a result of the experimental investigations, at each point such statistical characteristics as the average value $\bar{x}$ and dispersion $\sigma_{x}$ were calculated to discard the a priori false results that do not fall into the interval $\bar{x} \pm 3 \sigma_{x}$. The results of the experimental investigations are presented in a tabular form with the results displayed in the form $\bar{x} \pm 3 \sigma_{x}$.

\section{Results and discussions}

Based on the conducted experimental studies, the values of the average separation radius of a sample of the sunflower seeds were obtained depending on the air flow rate and the seed weight (Table 1).

Table 1

\section{Average radius of dispersion of the sample of the sunflower seeds} depending on the speed of the air flow and the mass of the seeds

\begin{tabular}{|c|c|c|c|c|c|c|}
\hline \multirow{3}{*}{$\begin{array}{c}\text { Mass } \\
\text { of the seeds, } \mathbf{g}\end{array}$} & \multicolumn{6}{|c|}{ Speed of the air flow, m. $\mathbf{s}^{-\mathbf{1}}$} \\
\cline { 2 - 7 } & 3.5 & 4.0 & 4.5 & 5.0 & 5.5 & 6.0 \\
\cline { 2 - 7 } & \multicolumn{2}{|c|}{$\begin{array}{c}\text { Distance of the seed displacement from the axis of the } \\
\text { central pipe of the aspiration channel, mm }\left(\bar{x} \pm 3 \sigma_{x}\right)\end{array}$} \\
\hline 0.035 & $35 \pm 6.3$ & $42 \pm 3.8$ & $55 \pm 5.0$ & $70 \pm 6.3$ & $78 \pm 8.4$ & - \\
\hline 0.041 & $32 \pm 3.8$ & $38 \pm 3.4$ & $45 \pm 6.5$ & $62 \pm 7.0$ & $60 \pm 5.4$ & - \\
\hline 0.047 & $30 \pm 4.5$ & $35 \pm 7.4$ & $42 \pm 6.3$ & $45 \pm 6.8$ & $48 \pm 7.2$ & - \\
\hline 0.054 & $25 \pm 3.8$ & $28 \pm 3.4$ & $28 \pm 2.5$ & $40 \pm 8.4$ & $45 \pm 6.8$ & $10 \pm 1.2$ \\
\hline 0.060 & $15 \pm 2.7$ & $25 \pm 5.3$ & $30 \pm 5.4$ & $38 \pm 5.7$ & $42 \pm 3.8$ & $20 \pm 4.2$ \\
\hline 0.074 & $10 \pm 0.9$ & $14 \pm 2.9$ & $15 \pm 3.2$ & $25 \pm 5.3$ & $40 \pm 4.8$ & $25 \pm 3.8$ \\
\hline 0.082 & $9 \pm 0.8$ & $12 \pm 2.5$ & $10 \pm 1.5$ & $20 \pm 1.8$ & $25 \pm 3.8$ & $29 \pm 4.4$ \\
\hline 0.090 & $10 \pm 1.8$ & $10 \pm 1.8$ & $10 \pm 1.5$ & $13 \pm 1.6$ & $12 \pm 1.8$ & $32 \pm 4.8$ \\
\hline 0.093 & $8 \pm 0.7$ & $9 \pm 0.8$ & $8 \pm 1.4$ & $12 \pm 1.8$ & $10 \pm 1.8$ & $45 \pm 4.1$ \\
\hline 0.100 & $7 \pm 0.6$ & $9 \pm 1.4$ & $9 \pm 1.6$ & $11 \pm 1.7$ & $12 \pm 2.2$ & $50 \pm 5.5$ \\
\hline
\end{tabular}

From the data given in Table 1, it is evident that, when the air flow rate is increased to $6.0 \mathrm{~m} \cdot \mathrm{s}^{-1}$, the lightest seeds are carried by the air stream from the receiving nozzles, located in the lower part, which requires the use of additional equipment to catch them. At the same time, at an air flow rate of $3.5-4.0 \mathrm{~m} \cdot \mathrm{s}^{-1}$, the seeds will not be able to enter the bin of the heavy fraction. Based on the experimental data presented in Table 1, using a PC, we plotted the dependence of splitting of the vertical path of the sunflower seeds upon their mass at different air flow rates (Fig. 3).

For the above reason, these graphs were not constructed for the air flow velocities of $3.5 \mathrm{~m} \cdot \mathrm{s}^{-1}$ and $6.0 \mathrm{~m} \cdot \mathrm{s}^{-1}$. The graphical dependencies, shown in Fig. 1, are obtained by approximating the experimental data by the least squares method in the Microsoft Excel 2010 software environment. As it is obvious from the graphs presented in Fig. 3, a sufficiently efficient velocity of the air flow inside the aspiration channel of the separator is a velocity of $5.5 \mathrm{~m} \cdot \mathrm{s}^{-1}$. At the indicated speed the heavy 
sunflower seeds change their path in such a way that they will fall by all means into the hopper for the particular fraction, and the light seeds, weighing up to $0.06 \mathrm{~g}$, will fall by all means into the hopper of the substandard fraction. Next, the length of the vertical aspiration channel of the separator was determined. For this, the average spacing distance of ten seeds of different masses was determined, depending on the length of the suction channel at a rational air flow rate (Table 2).

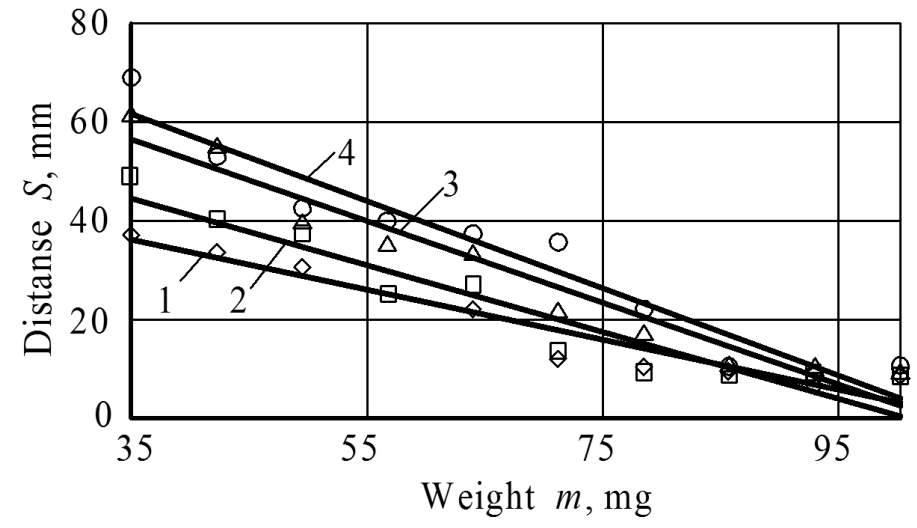

Fig. 3. Dependence of the splitting distance of the vertical path of the sunflower seeds upon their mass at different speeds of the air flow: $1-4.0 \mathrm{~m} \cdot \mathrm{s}^{-1} ; 2-4.5 \mathrm{~m} \cdot \mathrm{s}^{-1} ; 3-5.0 \mathrm{~m} \cdot \mathrm{s}^{-1} ; 4-5.5 \mathrm{~m} \cdot \mathrm{s}^{-1}$

From the data shown in Table 2, it is evident that, if the length of the aspiration channel is 0.1-0.4 m, the change in the path of the seeds relative to the axis of the central pipe is insignificant; therefore, the value of the indicated lengths of the aspiration channel was discarded. Based on the data of Table 2, we constructed the graphs of the dependence of the change in the vertical path of the seeds along the axis of the central pipe in the horizontal direction inside the suction channel depending on its length (Fig. 4).

Table 2

Average spacing distance of ten seeds of different masses depending on the length of the suction channel at a rational air flow rate

\begin{tabular}{|c|c|c|c|c|c|c|c|c|}
\hline \multirow{2}{*}{$\begin{array}{c}\text { Mass of } \\
\text { the seed, } \\
\mathbf{g}\end{array}$} & \multicolumn{7}{|c|}{ Length of the vertical aspiration channel, m } \\
\cline { 2 - 9 } & 0.1 & 0.2 & 0.3 & 0.4 & 0.5 & 0.6 & 0.7 & 0.8 \\
\hline 0.035 & $14 \pm 1.7$ & \multicolumn{7}{|c|}{$\begin{array}{c}\text { Displacement distance relative to the central axis of the vertical aspiration channel in a } \\
\text { horizontal direction, mm }\left(\bar{x} \pm 3 \sigma_{x}\right)\end{array}$} \\
\hline 0.041 & $13 \pm 2.3$ & $18 \pm 3.8$ & $24 \pm 3.6$ & $34 \pm 4.1$ & $50 \pm 9.0$ & $62 \pm 9.3$ & $65 \pm 9.8$ & $70 \pm 10.5$ \\
\hline 0.047 & $15 \pm 2.7$ & $16 \pm 3.4$ & $21 \pm 2.5$ & $32 \pm 3.8$ & $45 \pm 9.5$ & $55 \pm 8.6$ & $62 \pm 8.0$ & $65 \pm 5.9$ \\
\hline 0.054 & $11 \pm 2.0$ & $18 \pm 3.8$ & $18 \pm 2.2$ & $21 \pm 1.9$ & $32 \pm 7.6$ & $42 \pm 7.6$ & $45 \pm 6.8$ & $48 \pm 5.8$ \\
\hline 0.060 & $10 \pm 0.9$ & $15 \pm 2.7$ & $15 \pm 2.3$ & $18 \pm 1.6$ & $22 \pm 2.0$ & $25 \pm 3.8$ & $28 \pm 4.2$ & $42 \pm 3.8$ \\
\hline 0.074 & $9 \pm 1.4$ & $12 \pm 1.4$ & $11 \pm 1.7$ & $15 \pm 1.8$ & $15 \pm 1.4$ & $18 \pm 2.2$ & $20 \pm 4.2$ & $38 \pm 6.0$ \\
\hline 0.082 & $11 \pm 1.3$ & $13 \pm 1.6$ & $11 \pm 2.3$ & $12 \pm 2.5$ & $14 \pm 2.5$ & $11 \pm 1.7$ & $15 \pm 1.8$ & $25 \pm 3.0$ \\
\hline 0.090 & $9 \pm 1.9$ & $12 \pm 1.1$ & $10 \pm 1.8$ & $11 \pm 2.0$ & $11 \pm 1.7$ & $12 \pm 1.8$ & $13 \pm 1.2$ & $12 \pm 2.5$ \\
\hline 0.093 & $9 \pm 0.8$ & $9 \pm 1.9$ & $9 \pm 1.6$ & $9 \pm 1.6$ & $10 \pm 1.5$ & $9 \pm 1.9$ & $12 \pm 1.4$ & $10 \pm 0.9$ \\
\hline 0.100 & $10 \pm 0.9$ & $10 \pm 1.2$ & $9 \pm 1.6$ & $10 \pm 1.8$ & $10 \pm 0.9$ & $9 \pm 0.8$ & $11 \pm 1.7$ & $12 \pm 1.1$ \\
\hline
\end{tabular}

The graphs presented in Fig. 4 show that the most rational length of the suction channel is the length of $0.8 \mathrm{~m}$. Just at this length of the suction channel the heavy seeds (more than $0.06 \mathrm{~g}$ ) change their path by more than $40 \mathrm{~mm}$, which means that they will, by all means, fall into the hopper for the heavy fraction. In a similar way the rational value of the diameter of the aspiration channel was determined, namely, its value is $200 \mathrm{~mm}$. An increase in the diameter of the aspiration channel above this value leads to an increase in the energy costs to create an air flow. We have performed statistical simulation, carried out according to the Box-Benkin method. With this method each variable varies at three levels: $-1 ; 0 ; 1$, which significantly simplifies the experiment, reduces the material costs and the 
duration of the laboratory experiments in comparison with a full factorial experiment or with other central compositional plans. Experimental research was done for the sunflower seeds of the medium and heavy fractions. During the experiment, the percentage of the seeds was measured in the appropriate receiving hopper after separation. As responses the following values were used: $y_{1}-$ the percentage of the separated seeds of the heavy fraction contained in the hopper for the heavy fraction, $y_{2}$ - the percentage of the separated seeds of the medium fraction contained in the hopper for the medium fraction. For the factors affecting the separation process of the sunflower seeds into fractions, the following separator parameters were adopted: $V_{o}$ - the descent rate of seeds from the distribution cone, $\mathrm{m} \cdot \mathrm{s}^{-1} ; \alpha$ - the descent angle of seeds from the distribution cone, deg.; $V_{a f}$ - the air flow rate, $\mathrm{m} \cdot \mathrm{s}^{-1} ; \beta$ - the turning angle of the central pipe of aspiration, deg.; $a$ - the size of the sailing element, $\mathrm{mm}$.

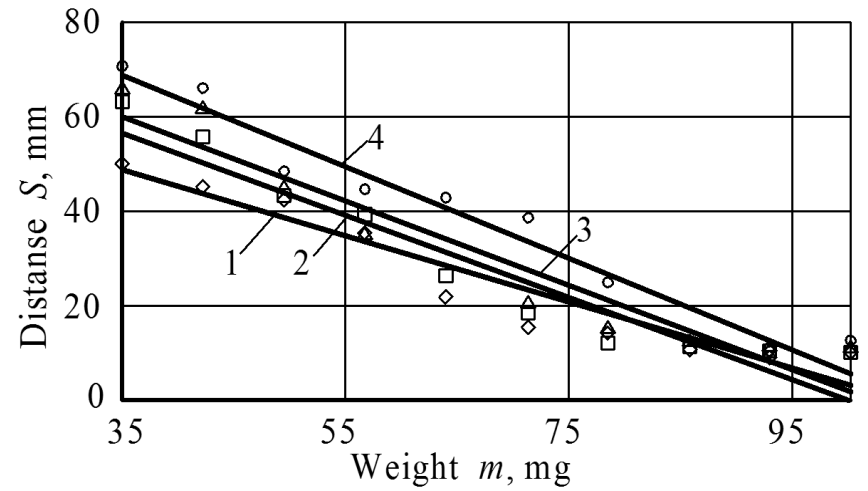

Fig. 4. Dependence of the distance by which the sunflower seed is deviated from its mass at a rational air flow rate and at the following lengths of the suction channel: $1-0.5 \mathrm{~m} ; 2-0.6 \mathrm{~m} ; 3-0.7 \mathrm{~m} ; 4-0.8 \mathrm{~m}$

In order to determine the parameters of the regression model, the least squares method was used [12-14]. The significance of the model parameters was checked by Student's test at a significance level of 0.05 The insignificant parameters were discarded. As a result, we obtained regression dependences of the indicated responses $y_{1}$ and $y_{2}$ from the normalised values of the factors, noted above, taking into account only the significant parameters. Adequacy of the obtained models was checked by Fisher's criterion [12].

We got that

$$
F_{p}=1.083<F_{t}=4.40,
$$

where $F_{p}$-estimated value of the criterion;

$F_{t}-$ its theoretical value, which confirmed the adequacy of the obtained regression models.

As a result of the transition from normalised to natural factors, we obtained the following regression dependence for the response $y_{1}$ :

$$
\begin{aligned}
y= & -1089.517 x_{1}+1905.589 x_{2}+82.258 x_{3}+0.139 x_{4}+6.547 x_{5}- \\
& -1120.935 x_{1}^{2}-0.076 x_{2}^{2}-6.968 x_{3}^{2}-0.024 x_{4}^{2}-0.311 x_{5}^{2},
\end{aligned}
$$

where $x_{1}=V_{\mathrm{o}} ; x_{2}=\alpha_{\mathrm{o}} ; x_{3}=V_{a f} ; x_{4}=\beta ; x_{5}=a$.

Based on the constructed regression model (1), using the methods of classical optimisation, the optimal values of the indicated parameters (factors) of the vibratory aspiration separator were found.

For this purpose we found all the necessary partial derivatives of the quadratic function $y_{1}$ with respect to the variables $x_{i}, i=\overline{1,5}$ which were equated to zero. The result is a system of five linear algebraic equations for unknowns $x_{i}, i=\overline{1,5}$, the solution of which is of the form:

$x_{1}=0.85 ; x_{2}=30.975 ; x_{3}=5.9025 ; x_{4}=283.5 ; x_{5}=10.5$ to prove that the solution obtained is a local maximum point, a Goes matrix was constructed, the elements of which are the values of the 
second partial derivatives at the obtained stationary point. After calculating all the major minors of this matrix, it turned out to be negatively defined. And this means that the found point is a point of local maximum, that is, at this point the function $y_{1}$ reaches its maximum value. Substituting the resulting solution into equation (1), we obtain the searched maximum value $y_{1}$ of the percentage of the seeds of the heavy fraction in the hopper for the seeds of the heavy fraction, namely, $y_{1}=91.008 \%$. Thus, at

$V_{o}=x_{1}=0.85 \mathrm{~m} \cdot \mathrm{s}^{-1} ; \alpha=x_{2}=30.975^{\circ} ; V_{a f}=x_{3}=5.9025 \mathrm{~m} \cdot \mathrm{s}^{-1} ; \beta=x_{4}=283.5^{\circ} ; a=x_{5}=10.5 \mathrm{~mm}$ the percentage $y_{1}$ of the seeds of the heavy fraction in the hopper of the seeds for the heavy fraction will be maximal and equal to $91.00 \%$, and the obtained values of the separator parameters will be optimal.

Fig. 5 shows graphs of the response surface for the fixed values of the factors: $y_{1}=y_{1}\left(V_{o}, \alpha, V_{a f}, \beta\right.$, $a)$ at fixed values of the factors: $\alpha=31^{\circ} ; \beta=283.5^{\circ} ; a=10.5 \mathrm{~mm}$.

Fig. 6 shows response surface graphs. $y_{1}=y_{1}\left(V_{o}, \alpha, V_{a f}, \beta, a\right)$ at fixed values of factors $V_{o}=0.85 \mathrm{~m} \cdot \mathrm{s}^{-1} ; \beta=283.5^{\circ} ; a=10.5 \mathrm{~mm}$.

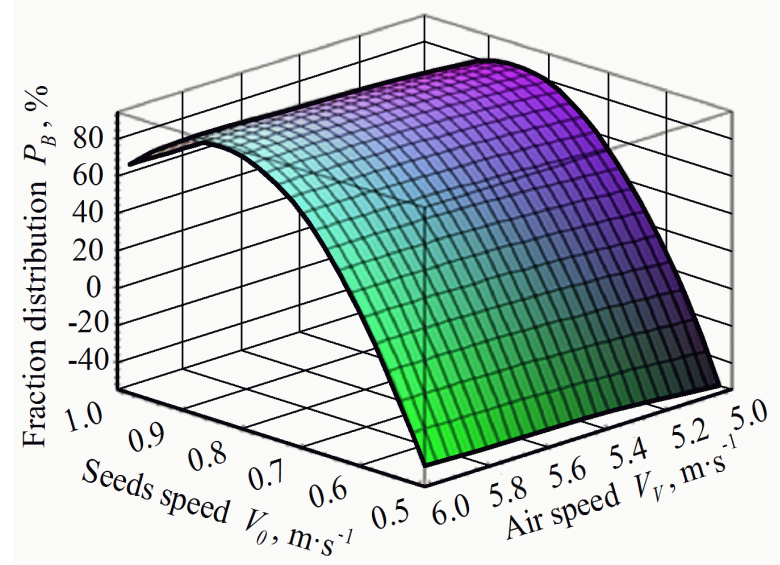

Fig. 5. Dependence of distribution of seeds of the heavy fraction on the descent rate $V_{o}$ of the seeds and the air velocity $\boldsymbol{V}_{a f}$, with fixed values of factors: $\alpha=31^{\circ} ; \beta=283.5^{\circ} ; a=10.5 \mathrm{~mm}$

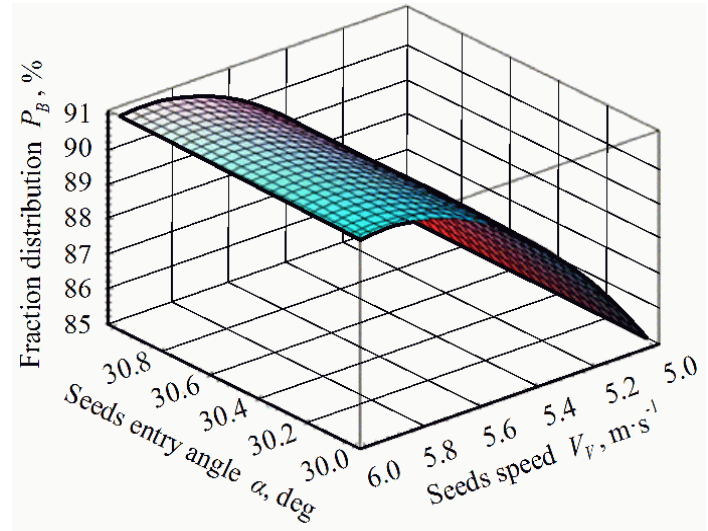

Fig. 6. Dependence of distribution of seeds of the heavy fraction upon the entry angle $\alpha$ of the seeds and the air velocity $V_{a f}$, with fixed values of factors: $V_{o}=0.85 \mathrm{~m} \cdot \mathrm{s}^{-1}$; $\beta=283.5^{\circ} ; a=10.5 \mathrm{~mm}$

Fig. 9 shows graphs of the response surface $y_{1}=y_{1}\left(V_{o}, \alpha, V_{a f}, \beta, a\right)$ for fixed values of factors: $\alpha=31^{\circ} ; \beta=283.5^{\circ} ; a=10.5 \mathrm{~mm}$.

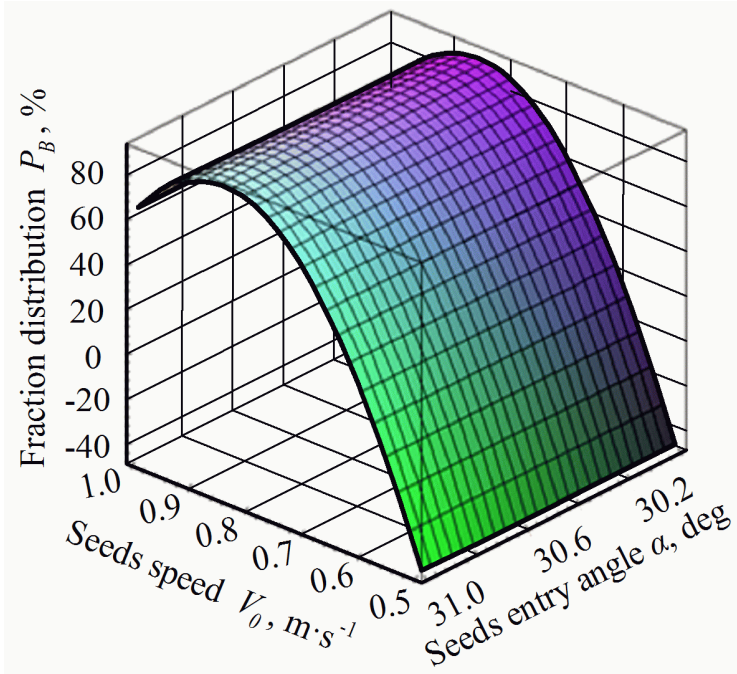

Fig. 7. Dependence of distribution of seeds of the heavy fraction on the descent rate $V_{\mathrm{o}}$ of the seeds and the entry angle $\alpha$ of the seeds, with fixed values of factors:

$$
V_{a f}=x_{3}=5.925 \mathrm{~m} \cdot \mathrm{s}^{-1} ; \beta=283.5^{\circ} ; a=10.5 \mathrm{~mm}
$$


Similarly the regression model is constructed for the response $y_{2}$ - the percentage of seeds of the medium fraction in the hopper for the medium fraction.

The regression equation in this case has the following form:

$$
\begin{aligned}
& y_{2}=-989.167+1717.766 x_{1}+4.805 x_{2}+80.718 x_{3}+ \\
& +0.0417 x_{4}+4.156 x_{5}-1033.008 x_{1}^{2}-0.0763 x_{2}^{2}- \\
& -6.811 x_{3}^{2}-0.727 \cdot 10^{-4} \cdot x_{4}^{2}-0.203 x_{5}^{2},
\end{aligned}
$$

were factors $x_{i}, i=\overline{1,5}$ mean the same parameters as in the previous case.

The adequacy of the obtained regression model by Fisher's criterion was also verified, and the significance of the coefficients of the variables in this model was tested by Student's criterion.

By the same methodology the optimal solution was found in this model, namely: $x_{1}=0.856$; $x_{2}=31.466 ; x_{3}=5.925 ; x_{4}=286.700 ; x_{5}=10.248$.

The maximum response value $y_{2}$ (percentage of the medium fraction in the hopper for the medium fraction) is $88.341 \%$. Thus, at

$V_{o}=x_{1}=0.856 \mathrm{~m} \cdot \mathrm{s}^{-1} ; \alpha=x_{2}=31.466^{\circ} ; V_{a f}=x_{3}=5.925 \mathrm{~m} \cdot \mathrm{s}^{-1} ; \beta=x_{4}=286.7^{\circ} ; a=x_{5}=10.248 \mathrm{~mm}$ the percentage $y_{2}$ of the seeds of the medium fraction in the hopper for the medium fraction will be maximum and equal to $88.341 \%$. Fig. 8 shows response surface graphs $y_{2}=y_{2}\left(V_{o}, \alpha, V_{a f}, \beta, a\right)$ at fixed values of factors: $V_{a f}=5.925 \mathrm{~m} \cdot \mathrm{s}^{-1} ; \beta=286.7^{\circ} ; a=10.248 \mathrm{~mm}$, but Fig. 9 - at fixed values of factors: $V_{o}=0.856 \mathrm{~m} \cdot \mathrm{s}^{-1} ; \beta=286.7^{\circ} ; a=10.248 \mathrm{~mm}$.

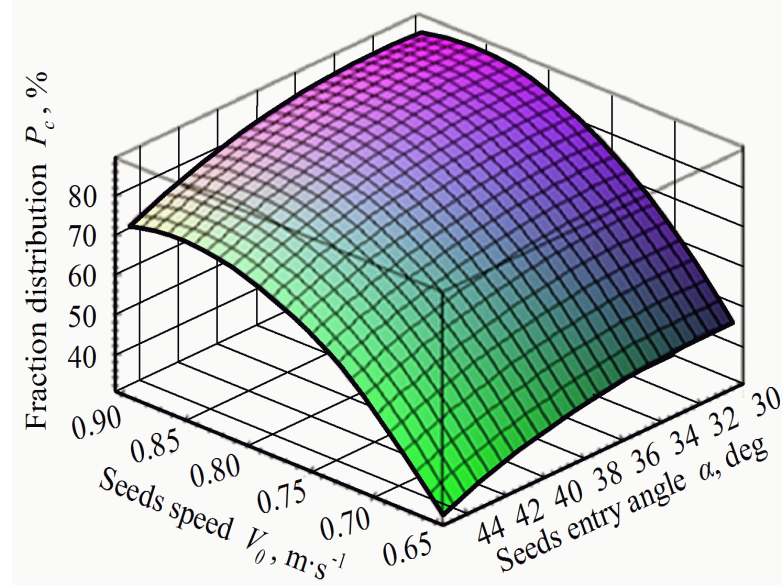

Fig. 8. Dependence of seed distribution of the medium fraction upon the descent rate $V_{o}$ of the seeds and the entry angle $\alpha$ of the seeds, with fixed values of factors: $V_{a f}=5.925 \mathrm{~m} \cdot \mathrm{s}^{-1}$; $\beta=286.7^{\circ} ; a=10.248 \mathrm{~mm}$

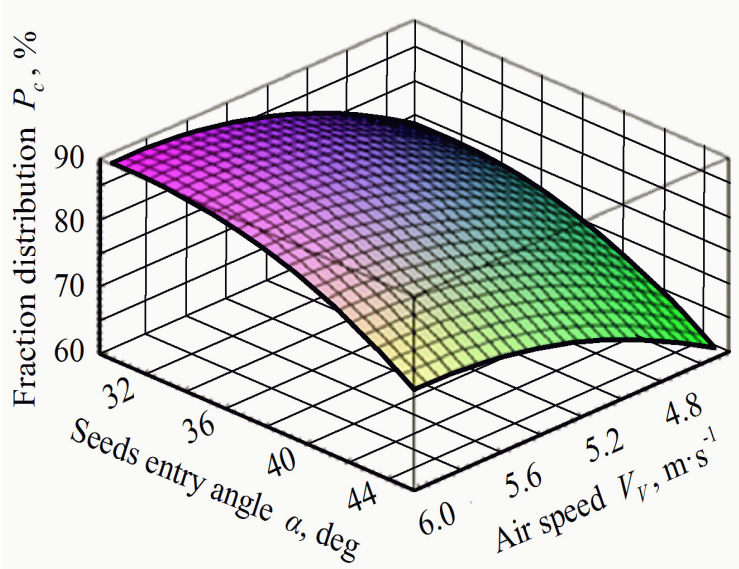

Fig. 9. Dependence of distribution of seeds of the medium fraction upon the air velocity $V_{a f}$ and the entry angle $\alpha$ of the seeds, with fixed values of factors: $V_{o}=0.856 \mathrm{~m} \cdot \mathrm{s}^{-1}$; $\beta=286.7^{\circ} ; a=10.248 \mathrm{~mm}$

Fig. 10 shows the graphs of the response surface $y_{2}=y_{2}\left(V_{o}, \alpha, V_{a}, \beta, a\right)$ at fixed values of factors $\alpha=31.466^{\circ} ; \beta=286.7^{\circ} ; a=10.248 \mathrm{~mm}$. As a result of statistical simulation on the PC the process of separating the sunflower seeds into fractions, three-dimensional graphs of the dependencies of the parameters of aspiration separation were constructed, which made it possible to determine the maximum values of the percentage of the selected seeds of the heavy fraction, which is $91.1 \%$. It was also established that the maximum percentage of the seeds of the medium fraction is $88.4 \%$.

This is achieved with the following parameters of the vibratory aspiration separation process: the rate of the seed descent $V_{o}$ from the surface of the conic distributor, equal to $0.85 \mathrm{~m} \cdot \mathrm{s}^{-1}$, the entry angle $\alpha$ of the seeds into the space of the aspiration channel, equal to $31^{\circ}$, the air flow velocity $V_{a f}$, equal to $5.90 \mathrm{~m} \cdot \mathrm{s}^{-1}$, the rotation angle $\beta$ of the aspiration channel, equal to $283.5^{\circ}$, and the height $\alpha$ of the sail element, equal to $10.5 \mathrm{~mm}$. Consequently, the obtained design results and experimental investigations witness about good perspectives of this development, which improves the technological process of separation of grain mixtures. 


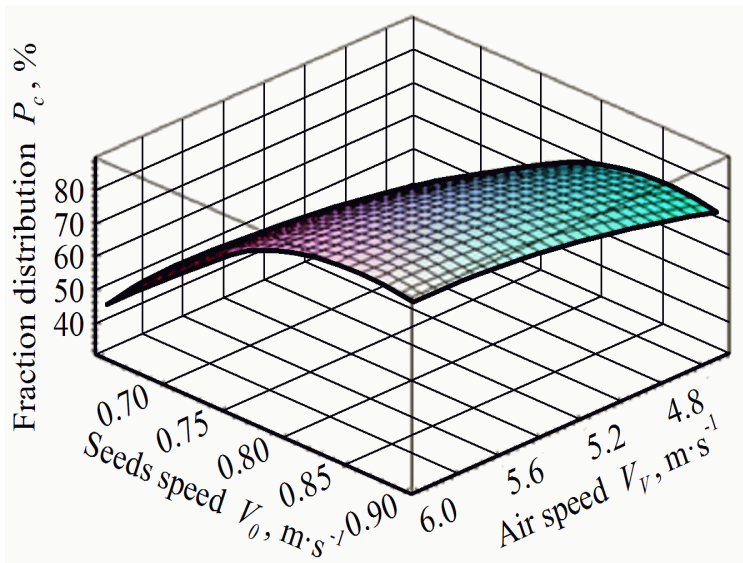

Fig. 10. Dependence of distribution of seeds of the medium fraction upon the descent rate $V_{o}$ of the seeds and the air velocity $V_{a f}$, with fixed values of factors:

$$
\alpha=31.466^{\circ} ; \beta=286.7^{\circ} ; a=10.248 \mathrm{~mm}
$$

\section{Conclusions}

1. As a result of the experimental studies, it was established that the rational speed of the air flow should be in the range $4.5-5.5 \mathrm{~m} \cdot \mathrm{s}^{-1}$. At this speed, the heavy sunflower seeds sufficiently change their path, so they will, by all means, fall into the hopper of the valuable fraction, while the light seeds, weighing up to $0.06 \mathrm{~g}$, will fall into the hopper of the substandard fraction. If the air flow rate is within the range $3.5-4.05 \mathrm{~m} \cdot \mathrm{s}^{-1}$, then the heavy seeds cannot get into the hopper of the valuable fraction.

2. The most rational length of the aspiration channel is $0.8 \mathrm{~m}$. It is this length of the aspiration channel, at which the heavy seeds (weighing more than $0.06 \mathrm{~g}$ ) change their path by more than $40 \mathrm{~mm}$, and, therefore, will definitely fall into the hopper of the valuable fraction.

3. The results of the experimental investigations show that the diameter of the aspiration channel should be equal to $200 \mathrm{~mm}$. At such value of the diameter of the aspiration channel, the heavy sunflower seeds will not reach the side wall of the aspiration channel. As a result, there will be no impact contact of the seeds with the side wall of the aspiration channel, and, therefore, an undesirable change in the necessary path of the seeds. Increasing the diameter of the aspiration channel over $200 \mathrm{~mm}$ leads to an increase in the energy costs for creating the air flow.

4. According to the results of statistical simulation of the investigated separation process of the sunflower seeds into the desired fractions, it was determined that the maximum percentage of the heavy fraction seeds, contained in the heavy fraction bin, is $91.1 \%$, the maximum percentage of medium fraction seeds, contained in the medium fraction bin, is $88.4 \%$, with the following parameters of the fibro-aspiration separation process being:

- rate $V_{o}$ of descent of the seeds from the surface of the distributor cone, equal to $0.85 \mathrm{~m} \cdot \mathrm{s}^{-1}$;

- angle $\alpha$ of entry of the seeds into the space of the aspiration channel, equal to $31^{\circ}$;

- air velocity $V_{a f}$ of the air flow, equal to $5.90 \mathrm{~m} \cdot \mathrm{s}^{-1}$;

- angle $\beta$ of rotation of the aspiration channel, equal to $283.5^{\circ}$;

- height $a$ of the sailing element, equal to $10.5 \mathrm{~mm}$.

5. For the sunflower seeds of the "EU Bella" variety with a mass of 1000 grains, equal to $60 \mathrm{~g}$, the recommended air flow rate should be $5 \mathrm{~m} \cdot \mathrm{s}^{-1}$, the length of the used vertical aspiration channel must be $0.7 \mathrm{~m}$, and, in addition, it is possible with $99.7 \%$ probability to separate efficiently the sunflower seeds of the heavy fraction with high varietal purity and full guarantee that they will fall into the separator hopper with the parameters of $28 \pm 4.2 \mathrm{~mm}$ (i.e. the inner diameter of the hopper intake is $23.8 \mathrm{~mm}$ and the outer diameter is $32.2 \mathrm{~mm}$ ).

\section{References}

[1] Gerasimenko E.O., Butina E.A., Kharchenko S.A., Achmiz E.P., Vorontsova O.S. Prospects of the "green" technologies of the complex processing of sunflower seeds. Research Journal of Pharmaceutical, Biological and Chemical Sciences. Vol. 7, Issue 2, 2016, pp. 609-623. 
[2] Tupkanjana P., Phalakornkule C. Development of activated carbons from sunflower seed husk for metal adsorption. Journal of Chemical Engineering of Japan, Vol. 40, Issue 3, 2007, pp. 222-227.

[3] Fattahi, S.H., Abdollahpour, S., Ghassemzadeh, H., Behfar, H., Mohammadi, S.A. Sunflower's seed separation in high-intensity electric field. Agricultural Engineering International: CIGR Journal, Volume 19, Issue 2, 2017, pp. 193-199.

[4] Lofty A. Constraction and performance evaluation of a local device for separating sunflower seeds and environment preservation. AMA, Agricultural Mechanization in Asia, Africa and Latin America. Vol. 40, Issue 1, 2009, pp. 73-77.

[5] Chavoshgoli E., Abdollahpour S., Abdi R., Babaie A. Engineering properties of sunflower seeds and materials other grain as moisture content for equipment of separator. Agricultural Engineering International: CIGR Journals, Volume 17 Issue 1, 2015, pp. 10-15.

[6] Aliev, E.B. Yaropud, V.M., Dudin, V.Y., Pryshliak, V.M., Pryshliak, N.V., Ivlev, V.V. Research on sunflower seeds separation by airflow. INMATEH - Agricultural Engineering, Vol. 56, Issue 3, 2018, pp. 119-128.

[7] Лещенко С.М., Васильковский А.Н., Васильковский М.И., Гончаров В.В. Повышение эффективности предварительной очистки зерновых смесей. (Improving the efficiency of pretreatment of grain mixtures). Сельскохозяйственные машины: сборник научных статей, Выпуск 18, 2009 Луцк. p. 230-234. (In Ukrainian).

[8] Кюрчев С.В., Колодий А.С. Анализ методов повышения урожайности сельскохозяйственных культур и требования к сепарируемому материалу (Analysis of methods for increasing yield and requirements for separated material). Сборник научных трудов Винницкого национального аграрного университета. Серия: Технические науки. Винница: ВНАУ, 2012. Выпуск 11. Том 2 (66). - pp. 322-327. (In Ukrainian).

[9] Кюрчев С.В., Колодий А.С. Многокритериальный анализ существующих сепараторов семян с различным рабочим орудием (Multicriteria analysis of existing seed separators with various working tools). Вестник Харьковского национального технического университета сельского хозяйства им. П. Василенко. Серия: технические науки / ХНТУСХ им. Петра Василенко. Харьков, 2015. Выпуск 156. Том 1. pp. 86-92. (In Ukrainian).

[10]Дацишин А.В., Ткачук А.И., Гвоздев О.В., Ялпачик Ф.Ю. Технологическое оборудование зерноперерабатывающих и масличных производств (Technological equipment for grain processing and oilseeds). Винница: «Новая книга», 2009. 486 с. (In Ukrainian).

[11]Васильковский М.И., Гончарова С.Я., Лещенко С.М. Обоснование параметров сепарации зерна в наклонном воздушном потоке (Substantiation of grain separation parameters in oblique air flow). Конструирование, производство и эксплуатация сельскохозяйственных машин: общегосударственный межведомственный научно-технический сборник, Выпуск 37, Кировоград, 2007. pp. 132-137. (In Ukrainian).

[12] Доспехов Б.А. Методика полевого опыта (Methodology of field experiments). 2012. Moscow: Nauka, 352 p. (In Russian).

[13]Веденяпин С.В. Общая методика экспериментальных исследований и обработки опытных данных (General methodology of experimental research and processing of experimental data), Москва: Колос, 1997, 159 р. (In Russian).

[14] Ivanovs, S., Adamovics, A., Rucins, A. Investigation of the technological spring harvesting variants of the industrial hemp stalk mass. Agronomy Research, Volume 13, Issue 1, 2015, pp. 73-80.

[15] Armitage D.M., Cook D.A., Duckett C. The use of an aspirated sieve to remove insects, mites and pesticides from grain. Crop Protection, Volume 15, Issue 8, 1996, pp. 675-680.

[16] Khamyev, V., Gulyev, A., Boiko, A. Justification of the design of pneumatic sorting machine for the preparation of selection seeds. MATEC Web of Conferences, 224, 2018.

[17] Badretdinov I., Mudarisov S., Tuktarov M., Dick E. Arslanbekova S. Mathematical modeling of the grain material separation in the pneumatic system of the grain-cleaning machine. Journal of Applied Engineering Science, 17, 2019. 